\title{
Keeping the faith! Drivers of participation in spiritually-based communities
}

\author{
Karen Granger ${ }^{\mathrm{a}}$, Vinh Nhat Lu ${ }^{\mathrm{b}}$, Jodie Conduit ${ }^{\mathrm{a}, *}$, Roberta Veale ${ }^{\mathrm{a}}$, Cullen Habel ${ }^{\mathrm{a}}$ \\ a The University of Adelaide, Business School (Marketing), Australia \\ b The Australian National University, College of Business and Economics, Australia
}

\section{A R T I C L E I N F O}

\section{Article history}

Received 1 August 2011

Received in revised form 1 December 2011

Accepted 1 May 2012

Available online 25 April 2013

\section{Keywords:}

Spiritual communities

Religiosity

Volunteering

Philanthropy

Social

Age

Income

\begin{abstract}
A B S T R A C T
Spiritually based communities (SBCs) provide a range of economic and social benefits to society. Declining memberships prompt a need for greater understanding and insight into the factors that drive participation in these communities. This study provides a conceptual model depicting religiosity as the core driver of donation of time, money and attendances at religious services. The model further indicates that the impact of belief in a 'higher being' on participation in SBCs is moderated by age, income, time available for socialization, desire to make a social contribution, and need for social interaction. A preliminary investigation in Australia provides strong support for the model, serving as a starting point for a number of future studies on the behaviors of SBC members.
\end{abstract}

Crown Copyright @ 2013 Published by Elsevier Inc. All rights reserved.

\section{Introduction}

Spiritually based communities (SBCs) refer to any religion-based organizations (Mankowski \& Rappaport, 2000). SBC members hold strong beliefs in a 'higher, supernatural being' and a common set of moral values and principals, that is 'ideals' that guide their daily lives (Cleveland \& Chang, 2009; Mokhlis, 2008). These communities provide significant social and economic benefits as a result of their members' contributions (Hassay \& Peloza, 2009; Mulyanegara, 2011) through various philanthropic works and services that benefit the disadvantaged, marginalized, disabled, and others in need (Wilson \& Musick, 1997a). Despite the increasing competition for donations in most developed countries, charities in the United States received an estimated $\$ 290$ billion of donations in 2010 (National Park Service, 2011).

In recent years, mainstream religious institutions in Europe and the United States are declining significantly in terms of membership and participation levels (Hirschle, 2010; Olson \& Beckworth, 2011) with regular attendance at recognized places of worship steadily declining since the 1990s (Olson \& Beckworth, 2011). While many people consider themselves spiritual, a smaller percentage commit to the perceived

\footnotetext{
The authors thank the three anonymous reviewers and Brian Engelland, the guest editor of this special issue, for their insights, suggestions and contributions to this paper. The authors thank Brett Scholz for his comments on an earlier version of the manuscript.

* Corresponding author at: The Business School, Faculty of the Professions, The University of Adelaide, 10 Pulteney Street, Adelaide 5000, Australia.

E-mail addresses: kgranger@sa.uca.org.au (K. Granger),vinh.lu@anu.edu.au

(V.N. Lu), jodie.conduit@adelaide.edu.au (J. Conduit), roberta.veale@adelaide.edu.au (R. Veale), cullen.habel@adelaide.edu.au (C. Habel).
}

constraints of an established religion (Bulik, 2009). Numerous reasons for this deterioration in commitment are known, including a lack of interest from younger audiences (Lee, 2010; Montgomery, Mitchell, Bauer, \& Turner, 2000), greater opportunity for leisure-time pursuits due to strong economic growth (Hirschle, 2010), the detrimental effect of perceived wrong-doings in some SBCs (Von Sinner, 2007), along with disenchantment with the level of perceived value provided (Kuzma, Kuzma, \& Kuzma, 2009).

The influence of religion in consumer behavior is a significantly under researched area (Cleveland \& Chang, 2009). While scholars have examined antecedents of SBC memberships, most of the research has been theoretical or qualitative in nature (Mankowski \& Rappaport, 2000). Some studies have focused on enhancing memberships by marketing religion and/or God as a form of commodity (Chen, 2011; Haq \& Wong, 2010) or investigated how religion (level of religiosity, denomination of religion, etc.) influences consumer reactions to marketing efforts and subsequent buying behaviors (Alam, Mohd, \& Hisham, 2011; Arham, 2010). In contrast, this research explores the extent to which an individual's belief in a supreme being or other supernatural forces drives their desire to belong and actively participate in an SBC. Specifically, the dimensions of membership and participation identified here are: giving freely of time (volunteering), donating money (Bonyhady, 2008; Craig-Lees, Harris, \& Lau, 2008) and attending religious services or formalized worship (Cornwall, 1989; Hollinger, Haller, \& Valle-Hollinger, 2007).

The study takes an important step in addressing a significant gap in the current understanding of how individual characteristics such as age, income, desire for social interaction, time for socialization, and desire to contribute to society moderate the expected relationship between 
spiritual beliefs (religiosity) and levels of participation in these activities. A conceptual framework is supported by a number of hypotheses that encapsulate these relationships, and the results of a preliminary study are given that provide the foundation for future research into this important stream of research.

\section{Theoretical background}

The role of religion continues to interest social science researchers and the wider community (Khraim, 2010; Mokhlis, 2009). In 20th century Western Europe, religious institutions lost much of their influence, resulting in the decline of both religious practice and beliefs (Olson \& Beckworth, 2011). In Great Britain and the United States, studies show relatively low religious influences in society (Hollinger et al., 2007); however, in many countries religion continues to play a central role in public and private life (Alam et al., 2011; Arham, 2010). Hence, greater understanding is needed of which factors, aside from religiosity, influence people's willingness to give their time and resources to SBCs.

\subsection{Religiosity}

While scholars define the concept in many different ways (King \& Boyatzis, 2004; Mokhlis, 2009), religiosity consistently includes three core aspects, regardless of religion or sect. First, at the core of religiosity is a strong belief in some form of supreme being, God, or some form of supernatural forces (Alam et al., 2011). Second, a set of common doctrines, or ideals that prioritizes caring for the collective above the individual and a rejection of materialism and greed (through activities such as donating time and money). Third, religiosity results in attendance at some kind of formalized worship and associated ceremonies (King \& Boyatzis, 2004). Reich, Oser, and Scarlett (1999) contrast the notions of spirituality and religiosity by stating that religiosity involves a relationship with a particular institutionalized doctrine about a supernatural power, a relationship that occurs through affiliation with an organized faith and participation in its prescribed rituals.

However, certain segments in modern society declare their belief in a higher being, but do not participate in an organized SBC (Bulik, 2009; Yip, 2011), indicating no inextricable linkage among the three dimensions of religiosity. Hence, for the purposes of this study religiosity refers to the degree to which an individual believes in the existence and power of a Supreme Being or God. Further, participation in SBCs is comprised of attendance at formalized worship services and donations of time and money.

Two precepts of conventional wisdom are prevalent among religious communities regarding contributions: (1) time and money contributions to the work of the religious communities are complementary, and (2) religious communities face growing competition with other charitable organizations for their members' contributions (Mulyanegara, 2011). However, other SBCs and secular charitable organizations are not the only competition they have. SBCs face competition from the increased demands placed on individuals in society stemming from work, family and desire to enjoy leisure activities (Gruber \& Hungerman, 2008; Hirschle, 2010). Nonetheless, belief in a higher spiritual being (religiosity) positively influences different forms of giving, membership and participation within SBCs (Cornwall, 1989; Park \& Smith, 2000; Wilson \& Musick, 1997b). This relationship is consistent, in spite of the ever-increasing competitive pressures (Lee, 2010) and other demands on people today (Gruber \& Hungerman, 2008). Based on this:

H1. Religiosity positively influences donations of time to an SBC.

H2. Religiosity positively influences donations of money to an SBC.

H3. Religiosity positively influences attendances at SBC worship services.

\subsection{The impact of age}

People typically experience SBCs during childhood but do not commit until later in life when they develop a greater understanding of specific doctrines and rules (Alam et al., 2011). Despite this trend, participation levels in SBCs traditionally remained stable with older people attending worship more frequently than younger people (Firebaugh \& Harley, 1991). However, significant decreases in participation from younger audiences are noted (Lee, 2010). Declining attendance at more traditional SBCs may be due to the younger generation's wish to distance themselves from scandals and other organizational crisis scenarios (Von Sinner, 2007), and/or a feeling that the SBCs are out of touch with their needs and fail to deliver enough value (Kuzma et al., 2009).

However, making social contributions is still important to many young people (Parboteeah, Cullen, \& Lim, 2004) with those between the ages of 25 and 40 years positive about volunteering (Burns, Reid, Toncar, Anderson, \& Wells, 2008). According to Howe and Strauss (2004), hard work on the reconstruction of communities, teamwork and civic spirit will define the generation born from 1982 onwards. Further, statistics show a large proportion of people in the USA between the age of 18 and 34 years consider themselves spiritual but do not belong to a specific SBC (Bulik, 2009). Hence, a substantial proportion of this important demographic volunteers and makes monetary donations elsewhere, while turning away from formalized worship and contributions to an SBC, in spite of their stated belief in a form of God.

While numerous studies investigate the behavior of younger age groups, none investigate the potentially moderating influence of age on attendance at worship and donations of time and money to SBCS simultaneously.

H4a. Age moderates the influence of religiosity on donations of time.

H4b. Age moderates the influence of religiosity on donations of money.

H4c. Age moderates the influence of religiosity on attendances at SBC worship services.

\subsection{The impact of income}

Surprisingly, the relevance of the role of income with respect to participation in SBCs has received little attention (Schwadel, McCarthy, \& Nelsen, 2009). Scholars suggest higher incomes lead to greater attendance at formalized worship (Sawkins, Seaman, \& Williams, 1997), with some inconsistencies (Schwadel, 2011).

Sawkins et al. (1997) find that religious attendance increases when wages increase at the lower end of the wage spectrum, but the effect of wages is minimal at higher levels. As wages increase at the lower end of the spectrum, individuals' needs to work long hours reduce giving them more time to attend formal worship. In contrast, at the upper end of the earnings spectrum, individuals reallocate their time towards work, or if costs of non-religious leisure activities are higher than the costs of religious participation, those with high incomes can afford to substitute non-religious leisure time for less costly religious attendance (Sawkins et al., 1997).

Research on philanthropic pursuits also demonstrates that people are more involved in activities such as volunteering once their basic needs are satisfied through higher income levels (Parboteeah et al., 2004; Wilson \& Musick, 1997b). The relationship between religious activity and civic activity (or philanthropy) is an individual-level relationship, with high-income members more prone to participate in these activities (Schwadel, 2005). Additionally, given an orientation to giving is a universal philosophy across all major religious groups, those with higher incomes are able to make regular donations of money to an 
SBC, even if the pressures of work and other secular activities prevent regular volunteering of time (Cleveland \& Chang, 2009). This study tests the potentially moderating influence of income on the relationships between religiosity and donations of time and money and attendance at worship.

H5a. Income moderates the influence of religiosity on donations of time.

H5b. Income moderates the influence of religiosity on donations of money.

H5c. Income moderates the influence of religiosity on attendances at SBC worship services.

\subsection{Desire to contribute to society}

Philanthropic activities are about giving and volunteering, where contributions are made without reward. The emergence of organized secular philanthropy in the Western tradition occurred in the early 17th century (Bonyhady, 2008). Major religions historically viewed material possessions negatively, instead promoting the virtues of giving, sharing and sacrificing (Cleveland \& Chang, 2009). Consequently, many philanthropically based organizations have religious backgrounds (Ruiter \& de Graaf, 2006).

Participation in an SBC includes the pursuit of two key philanthropic pursuits, the donation of time and money. Wilson (2000) considers volunteering to include any activity involving a free donation of time to benefit another person, group or organization. In many developed countries levels of volunteering have peaked, perhaps because of the lack of positive and relevant images with which people want to associate (Hankinson \& Rochester, 2005). In order to reshape perceptions of volunteering, Hankinson and Rochester (2005) recommend marketing a solution rather than marketing the problem. Professionals, and those with better education, tend to do more volunteering because they are self-directed and they believe that community service may also support professional interests (Wilson \& Musick, 1997b). Callow (2004) claims that in order to develop recruitment campaigns, organizations relying on volunteers as a resource need to highlight the various appeals of volunteering by understanding the motives and the perceived personal benefits of volunteering.

Studies indicate a positive relationship between philanthropy and religion (Parboteeah et al., 2004). In spite of the decline in membership and participation within SBCs, philanthropy continues to increase in terms of the number of individuals who contribute time and money to various social and community causes (Craig-Lees et al., 2008; Hankinson \& Rochester, 2005). Hence, this study investigates the potentially moderating influence of desire to contribute to society on the relationship between religiosity and donations of both time and money.

H6a. The desire to contribute to society moderates the influence of religiosity on donations of time.

H6b. The desire to contribute to society moderates the influence of religiosity on donations of money.

\subsection{Desire for social interaction}

The need to belong is a fundamental human motivator (Baumeister \& Leary, 1995). Communities are the result of human interrelationships formed to address individuals' needs for social contact, to be part of a group and realizing a sense of belonging (Koh \& Kim, 2003). People readily form social bonds and social networks where they have something in common or share experiences with others in a given group (Kossinets \& Watts, 2006). As social beings, most people live in a matrix of relationships that largely defines their identity
(Mellor, Stokes, Firth, Hayashi, \& Cummins, 2008). Some communities are ideological, whether political, economic or religious based (Hillery, 1971).

Social group level influences have the potential to affect community and group participation within SBCs. Studies have shown that normative influences of others' expectations are generally in the context of social needs rather than personal needs (Craig-Lees et al., 2008). These social influences of group behaviors are important, especially in terms of how they impact membership and participation in SBCs. Indeed, the need for social involvement has a positive relationship with religious and spiritually motivated consumption (Cornwall, 1989; Park \& Smith, 2000). However, little knowledge exists about the impact that this desire for social interaction has on the relationship between religiosity and formalized worship.

This research provides insight specific to this gap.

H7. The need for social interaction moderates the influence of religiosity on attendance at SBC worship services.

\subsection{Time for socialization}

SBCs face increased competition from the opportunity cost of the time individuals devote to work, family and leisure (Gruber \& Hungerman, 2008; Hirschle, 2010). Similarly, these factors place constraints on an individual in their interactions with SBCs. Individuals with a desire to attend formalized worship or donate time to SBC activities may not have the time resources to put to such interaction. This study incorporates an overarching variable, time for socialization, which relates to a range of respondent variables and provides a rationalization for us to utilize them as control variables in the pilot study (see Section 3.2).

Individuals split their time according to paid work, unpaid work and personal care time and increased demand in any of these categories impacts on their 'uncommitted' time (Andorka, 1987) and only this can be time for socialization, including formalized worship or volunteer activities (Miller \& Nakamura, 1996). Variables such as gender and family structure (Craig \& Bittman, 2008) and education and employment status (Goodin, Rice, Bittman, \& Saunders, 2005) show a vast set of interrelationships to these time expenditures.

Sundeen, Raskoff, and Garcia (2007) provide a comprehensive review of the barriers to volunteering, where lack of time featured prominently in all of their reviewed studies. Given that time pressures on individuals potentially thwart good intentions, the following is hypothesized:

H8a. Time available for socialization moderates the relationship between religiosity and donations of time.

H8b. Time available for socialization moderates the relationship between religiosity and attendances at SBC worship services.

\section{Exploratory study}

This exploratory research serves as a preliminary test of hypotheses. van Teijlingen and Hundley (2001) note that such studies can provide valuable insights for other researchers, such as the testing of data collection approaches, some indication of required future sample size, and considerations of suitable outcome measures for future investigations (Lancaster, Dodd, \& Williamson, 2004).

\subsection{Data collection}

In order to achieve some preliminary insights into the drivers of participation in SBCs, the hypothesized model was tested on a nonprobability sample $(n=163)$ of respondents aged 18 years and older in Australia. Participants received notifications in a newsletter associated 
with a volunteering organization in a large metropolitan area. Social media publications were employed and invited participants to pass the survey link on to friends and contacts. The purposive sampling methodology yielded substantial variability within the hypothesized variables, serving to demonstrate the adequacy of the research instruments and indicate the feasibility of a full scale research study (van Teijlingen \& Hundley, 2001). A comparison of early and late responses indicated no significant differences among groups (Armstrong \& Overton, 1977).

Further, age and other demographic distributions aligned reasonably well to the general Australian population. Though a slight female bias is recognized, results are not expected to be severely limited (see Table 1 for sample profile). A breakdown of faith affiliations indicates that $7.4 \%$ of the respondents were members of the Anglican Church, 14.1\% Catholics, and 24.5\% members of Uniting Church. An additional $13.5 \%$ of the sample indicated other Christian as their main faith, while $9.8 \%$ and $30.7 \%$ of the respondents followed another religion or did not follow any religion respectively.

\subsection{Measurements and results}

Existing measures from the literature were employed for this exploratory study (Appendix 1). Results of the confirmatory factor analysis indicate a good fit between the data and the measurement model $\left(\chi^{2}=165.84\right.$, d.f $=98, \mathrm{CFI}=0.96, \mathrm{GFI}=0.89, \mathrm{TLI}=0.95, \mathrm{NFI}=$ 0.91 , RMSEA $=0.06$, SRMR $=0.06$ ). Table 2 provides descriptive statistics and the correlation matrix of the constructs.

Hypothesis testing involved a series of hierarchical regression analyses (Tables 3, 4, and 5), utilizing Aiken and West's (1991) procedures. In each table, Model 1 highlights the impact of the control variables, including gender, level of education, faith affiliations, membership of interest groups, and membership of other communities. The control of these variables was important for various reasons. For instance, the literature on religions, religious beliefs and behaviors suggests a significant gender differences in terms of religiosity (Miller \& Stark, 2002). Researchers have further highlighted the debate on the potential (both positive and negative) correlations between level of education attainment and attendance at religious services (Albrecht \& Heaton, 1984). Faith affiliations were controlled for because some faiths are much more aggressive in terms of donations than others (Benjamin, Choi, \& Fisher, 2010). The other control variables in the study included memberships of interest groups and other communities, which clearly influence the extent of involvement and volunteering/donation of the respondents.

While Model 2 shows the impact of religiosity on each dimension of SBC participation, Model 3 indicates the additional direct effects of the hypothesized moderators. Model 4 specifies the two-way interaction effects between religiosity and the moderator variables, via the inclusion of the relevant multiplicative and centered term between religiosity and each moderator variable.

Table 1

Sample profile.

\begin{tabular}{lrll}
\hline & Freq & $\%$ & ${ }^{\mathrm{a}} \mathrm{ABS} \%$ \\
\hline Gender & & & \\
Male & 50 & $30.7 \%$ & $49.6 \%$ \\
Female & 113 & $69.3 \%$ & $50.4 \%$ \\
Total & 163 & $100 \%$ & $100 \%$ \\
Age & & & \\
$18-25$ years & 19 & $11.7 \%$ & $20.5 \%$ \\
$26-35$ years & 33 & $20.2 \%$ & $23.6 \%$ \\
$36-45$ years & 30 & $18.4 \%$ & $27.5 \%$ \\
$46-55$ years & 26 & $16.0 \%$ & $13.2 \%$ \\
Over 55 years & 55 & $33.7 \%$ & $15.2 \%$ \\
Total & 163 & $100 \%$ & $100.00 \%$ \\
\hline
\end{tabular}

a Source: ABS (2006).
The results support all hypotheses, with the exception of $\mathrm{H} 4 \mathrm{c}, \mathrm{H} 5 \mathrm{c}$, and H7. More specifically, religiosity has a positive and significant relationship with all three dimensions of participation in SBCs. This supports the notion that people who are 'religious' are more likely to contribute, and contribute more, than those who are not religious (Park \& Smith, 2000; Wilson \& Musick, 1997a, 1997b), further confirming a positive relationship between philanthropy and religion (Parboteeah et al., 2004). In addition, several moderator variables that influence these relationships, including age, income, time for socialization, and desire to contribute to society occur (Fig. 1).

The moderating role of age appeared to be complex in its nature and influence. Of interest was the opposing moderating affect that age had on the relationships between religiosity and the donation of time and money respectively. The two different moderating effects indicate that an individual expresses their religiosity in a different manner depending on their age. Younger people tended to express their religiosity in donation of time, whereas older people expressed their religiosity via donations of money. Younger individuals may be under more pressure in terms of disposable income, as they allocate resources towards family and career associated costs. Consequently, even with a strong sense of religiosity they do not have the relative financial resources to make donations, leading to a weaker relationship between religiosity and the donation of money. People at the lower end of the age spectrum will have children involved in activities in their SBCs, hence increasing opportunities for their own donation of time. In contrast, older people, with higher relative disposable income, tend to donate more money. Further, the lack of support for a moderating influence of age on formalized worship attendances indicates that age does not play a major role in determining membership within an SBC. This finding is contradictory to the general argument that age is a key factor influencing formalized worship (Montgomery et al., 2000) and demonstrates that the age-effect warrants further investigation.

Consistent with previous research (Schwadel, 2005), this exploratory study confirms the positive moderating role of income on the relationship between religiosity and propensity to donate money. However, this endeavor to engage in philanthropic pursuits did not extend to the giving of more time. This runs counter to the argument that those at high income levels engage in more volunteering (Parboteeah et al., 2004) and infers that the pressures of work and other secular activities prevent regular volunteering of time by higher income groups (Cleveland \& Chang, 2009). Despite previous research suggesting that income is a predictor of attendance at church attendance (Sawkins et al., 1997), this study found no evidence that income moderated the relationship between religiosity and attendance at worship.

A desire to contribute to society significantly moderates the relationship between religiosity and donations of both time and money. The influence of religiosity on donations is stronger for individuals with a lower desire to contribute to society. This finding suggests that individuals with a high penchant for donating will consider competing avenues to contribute to society. Individuals with less of a philanthropic orientation will contribute to the SBC perhaps out of a moral obligation.

Further, the need for social interaction does not moderate the relationship between religiosity and frequency of service attendances. Hence, congregations do not attend religious or spiritual services primarily for the social interaction. Perhaps this behavior is because in modern society people are highly mobile and can socialize through many different physical and virtual communities. Therefore, people's need for social interaction should not serve as a focal point in a marketing strategy that aims to increase attendance at formal worship services. What is more important is the time available for socialization.

Indeed, individuals with significant time available for socialization tend to attend formalized worship more regularly, as this variable had a positive moderating effect on the relationship with religiosity. This 
Table 2

Descriptive statistics and correlation matrix.

\begin{tabular}{|c|c|c|c|c|c|c|c|c|c|c|c|}
\hline Construct & Mean & SD & 1 & 2 & 3 & 4 & 5 & 6 & 7 & 8 & 9 \\
\hline 1. Religiosity & 5.0 & 2.65 & 1 & & & & & & & & \\
\hline 2. Social contribution & 7.5 & 1.38 & $0.20^{*}$ & 1 & & & & & & & \\
\hline 3. Socialization desire & 5.2 & 1.80 & $0.21^{* *}$ & $0.19^{*}$ & 1 & & & & & & \\
\hline 4. Age & 46.3 & 16.29 & -0.05 & $-0.19^{*}$ & $-0.29^{* *}$ & 1 & & & & & \\
\hline 5. Income & 3.4 & 1.40 & -0.01 & 0.06 & -0.05 & 0.02 & 1 & & & & \\
\hline 6. Time for socialization & 5.4 & 1.23 & 0.07 & 0.10 & 0.12 & -0.07 & -0.01 & 1 & & & \\
\hline 7. Time donated & 2.7 & 5.91 & $0.43^{* *}$ & 0.01 & 0.07 & -0.10 & -0.14 & 0.08 & 1 & & \\
\hline 8. Money donated & 47.2 & 105.36 & $0.47^{* *}$ & 0.01 & -0.04 & $0.17^{*}$ & $0.16^{*}$ & -0.04 & $0.42^{* *}$ & 1 & \\
\hline 9. Services attended & 2.2 & 2.29 & $0.74^{* *}$ & $0.24^{* *}$ & $0.16^{*}$ & -0.10 & -0.01 & 0.07 & $0.49^{* *}$ & $0.50^{* *}$ & 1 \\
\hline
\end{tabular}

* $\mathrm{p}<0.05$.

$* * \mathrm{p}<0.01$.

finding supports the notion that many people have a spirituality and belief in a 'higher being' but do not attend worship due to time constraints (Gruber \& Hungerman, 2008; Yip, 2011). Similarly, those with time for socialization also demonstrate a greater propensity to donate time to the SBC, consistent with recent literature on volunteering (Sundeen et al., 2007).

\section{Implications, limitations and directions for future research}

\subsection{Implications for marketers of SBCS}

The preliminary findings in this study emphasize that an individual's desire to be spiritual will drive them to provide 'good works' to society; but without necessarily doing so within a formalized SBC. This presence of competition in the world of religion is consistent with those who advocate the secularization theory, including sociologist, Peter Berger, who argues, "religion has to be marketed" (1967, p.137). Given the highly competitive market facing religious institutions and charities, the non-profit sector has become more aggressive and creative in its efforts to educate and ultimately attract both individual and corporate benefactors (Hassay \& Peloza, 2009). Hence, understanding the driving forces and moderators of participation in SBCs is critical to marketers today.

Overall the research provides a number of insightful implications for management and leaders of SBCs. Importantly, the conditions under which people participate in SBCs are revealed and new ways for these communities to view membership and contributions are provided. Managers of SBCs will benefit from a better understanding of the antecedents that predict behavior of attending religious

Table 3

Hierarchical regression analyses: donation of time.

\begin{tabular}{lcrrr}
\hline Variables & Model 1 & Model 2 & Model 3 & Model 4 \\
\hline Gender & 0.46 & 1.03 & 1.31 & 1.66 \\
Education & 0.21 & -0.13 & 0.08 & 0.30 \\
Faith affiliations & $-2.16^{* *}$ & 0.55 & 0.30 & -0.05 \\
Community group memberships & 1.56 & 0.59 & 0.67 & 1.00 \\
Other interest group memberships & -0.85 & -0.63 & -0.16 & -0.26 \\
Religiosity & & $5.41^{* * *}$ & $5.45^{* * *}$ & $5.45^{* * *}$ \\
Age & & -1.49 & -1.52 \\
Income & & -1.67 & $-1.81^{*}$ \\
Time for socialization & & 0.84 & 0.86 \\
Desire to contribute to society & & & -1.27 & -1.48 \\
Religiosity $\times$ age & & & & $-2.27^{* *}$ \\
Religiosity $\times$ income & & & & $-1.71^{*}$ \\
Religiosity $\times$ time for socialization & & & & $-2.05^{* *}$ \\
Religiosity $\times$ social contribution & & & & \\
$\mathrm{R}^{2}$ & 0.05 & $0.20^{* * *}$ & $0.23^{* * *}$ & $0.32^{* * *}$ \\
$\Delta \mathrm{R}$ & & $0.15^{* * *}$ & 0.03 & $0.09^{* * *}$ \\
\hline *** $\mathrm{p}<0.01$. & & & \\
$* * \mathrm{p}<0.05$. & & &
\end{tabular}

services, giving freely of time and donating money. They can also minimize the potential risks of investment in some areas of marketing. For example, SBCs' efforts in marketing strategies based on targeting people's social needs or sense of belonging will likely prove to be fruitless. Overall, the findings provide valuable understanding of the behavioral predictors useful for managers in their efforts to develop the most effective strategies to increase membership and contributions in order to address the decline within their communities or build new communities.

To successfully market an SBC, understanding the potential for differing market segments emerging from the framework is critical. Individuals exist that participate in the SBC through formalized worship services that do not donate freely of their time and money. Some patrons provide financial support to the institution, but do not participate in civil activities beyond the SBC. Yet other participants within the SBC donate their time but limited money. Another segment in society contributes time or resources to charitable associations without wanting these associations to be linked to an SBC, or indeed without any awareness of the charities association with an SBC.

\subsection{Limitations and directions for future research}

The objective of the exploratory study to provide support for the conceptual framework is achieved; however, a number of limitations to the generalizability of results are readily acknowledged. These include a bias towards location, gender, ethnicity and religious orientation in the small non-probability sample. To comprehensively test this model and realize generalizable results, a future study (or studies) needs extensive geographic, cultural and denominational scope. This requires data collection in a number of international locations providing access to diverse ethnicity and a broad representation of religious

Table 4

Hierarchical regression analyses, donation of money.

\begin{tabular}{|c|c|c|c|c|}
\hline Variables & Model 1 & Model 2 & Model 3 & Model 4 \\
\hline Gender & $2.90^{* * *}$ & $3.72^{* * *}$ & $3.17^{* * *}$ & $3.07^{* * *}$ \\
\hline Education & 1.08 & 0.80 & 0.51 & 0.45 \\
\hline Faith affiliations & $-4.12^{* * *}$ & -1.24 & -0.95 & -0.75 \\
\hline Community group memberships & $1.83^{*}$ & 0.85 & 0.86 & 0.33 \\
\hline Other interest group memberships & 0.38 & 0.72 & 0.23 & -0.01 \\
\hline Religiosity & & $5.62^{* * *}$ & $5.90^{* * *}$ & $2.32^{* *}$ \\
\hline Age & & & $1.77^{*}$ & $1.90^{*}$ \\
\hline Income & & & $2.13^{* *}$ & $2.39^{* *}$ \\
\hline Desire to contribute to society & & & -0.68 & -1.03 \\
\hline Religiosity $\times$ age & & & & $2.59^{* *}$ \\
\hline Religiosity $\times$ income & & & & $2.18^{* *}$ \\
\hline Religiosity $\times$ social contribution & & & & $-1.74^{*}$ \\
\hline $\mathrm{R}^{2}$ & $0.15^{* * *}$ & $0.29^{* * *}$ & $0.33^{* * *}$ & $0.40^{* * *}$ \\
\hline$\Delta R^{2}$ & & $0.14^{* * *}$ & $0.04^{* *}$ & $0.07^{\text {*** }}$ \\
\hline \multicolumn{5}{|l|}{ *** $\mathrm{p}<0.01$} \\
\hline \multicolumn{5}{|l|}{$* * \quad \mathrm{p}<0.05$} \\
\hline$* \mathrm{p}<0.10$ & & & & \\
\hline
\end{tabular}


Table 5

Hierarchical regression analyses, attendances at SBC worship services.

\begin{tabular}{|c|c|c|c|c|}
\hline Variables & Model 1 & Model 2 & Model 3 & Model 4 \\
\hline Gender & $-0.04^{*}$ & 1.05 & 1.37 & 1.41 \\
\hline Education & 0.82 & 0.36 & 0.35 & 0.33 \\
\hline Faith affiliations & $-5.48^{* * *}$ & -1.07 & -1.06 & -1.37 \\
\hline Community group memberships & $2.26^{* *}$ & 0.76 & 0.72 & 0.80 \\
\hline Other interest group memberships & -0.33 & 0.17 & 0.43 & 0.19 \\
\hline Religiosity & & $11.10^{* * *}$ & $10.72^{* * *}$ & $6.45^{* * *}$ \\
\hline Age & & & -1.34 & -1.44 \\
\hline Time for socialization & & & 0.36 & 0.98 \\
\hline Need for social interaction & & & -0.00 & -0.18 \\
\hline Income & & & -0.36 & -0.31 \\
\hline Religiosity $\times$ age & & & & -1.19 \\
\hline Religiosity $\times$ time for socialization & & & & $2.12^{* *}$ \\
\hline Religiosity $\times$ social interaction need & & & & 0.88 \\
\hline Religiosity $\times$ income & & & & 0.56 \\
\hline $\mathrm{R}^{2}$ & $0.20^{* * *}$ & $0.55^{* * *}$ & $0.56^{* * *}$ & $0.59^{* * *}$ \\
\hline$\Delta R^{2}$ & & $0.35^{\text {*** }}$ & 0.01 & $0.03^{* *}$ \\
\hline
\end{tabular}

doctrines and SBCs. Ideally, a cross-cultural study would include countries where populations within a given religious group have different documented levels of engagement with similar forms of SBCs. Few papers attempt cross-cultural and cross-denominational comparisons, and these primarily investigate differences in purchasing behaviors and reactions to marketing efforts as opposed to understanding the drivers of participation in alternative denominations of SBCs (Cleveland \& Chang, 2009; Haq \& Wong, 2010).

A common philosophy across all major religions is that individuals need to control hedonistic desires and avoid behaviors associated with greed, anger and hate. Forms of greed such as materialism have gained particular attention from business researchers, due to their interest in its effects on consumer accumulation of material assets and purchasing behaviors (Cleveland \& Chang, 2009; Mokhlis, 2008). This study proposes that an individual's income level is a positive moderator of the relationship between religiosity and monetary donations but negatively moderates the relationship with donation of time. This study does not seek to investigate respondents' attitudes towards materialism or levels of personal wealth specifically as moderators of donations of time and/or money. Given Cleveland and
Chang's (2009) findings on the influence of ethnic identity and religiosity on materialism, future research needs to incorporate this attitudinal dimension in distinctive SBCs in different locations.

In examining an individual's willingness to donate their time, an implicit assumption is made that individuals have both an attitudinal desire to donate as well as the resource (time) to dedicate. The research investigates this by testing 'time available for socialization' as a moderating factor. However, previous studies have used other surrogates for 'time' such as presence and age of children in the home (Schwadel, 2005) or lifecycle stage (Craig \& Bittman, 2008). Another potentially important consumer characteristic is work status and hours worked, as those working long hours do not have the time or mental energy to be active volunteers. Scholars should empirically test these alternative variables to understand their influences on volunteering behaviors within the SBC context. Furthermore, the "time" variable might be expanded to include dimensions such as time available for volunteering and worship, as well as socialization.

Future research should investigate the differing market segments that are emerging, taking into consideration the implications of broader economic and popular culture factors. Many Western countries have seen the proliferation of various charitable and religious organizations reflecting the presence of these different segments and different values in society. For example, while attendances at many traditional Christian SBC services are declining, in the United States the growth of 'mega-churches', such as large Protestant congregations with regular attendances in excess of 2000 worshipers, is an example of SBCs flourishing against these trends (Kuzma et al., 2009). Additionally non-profit organizations, such as the Alliance Defense Fund and Family Research Council (supporting a Christian and Judeo-Christian view respectively) have successfully emerged. Some may believe such organizations to be SBCs without regular formalized worship. Future research should investigate what these organizations are perceived to offer in terms of value to their participants that are absent in more traditional entities. Researchers should also conduct future examinations on the influence of age and other demographics, taking into account various extents of involvement in different forms of SBCs and secular charity organizations. Further scope also exists to examine which categories of needs (spiritual and otherwise) are specific to segments in the broader community, utilizing a cross cultural and cross denominational approach.

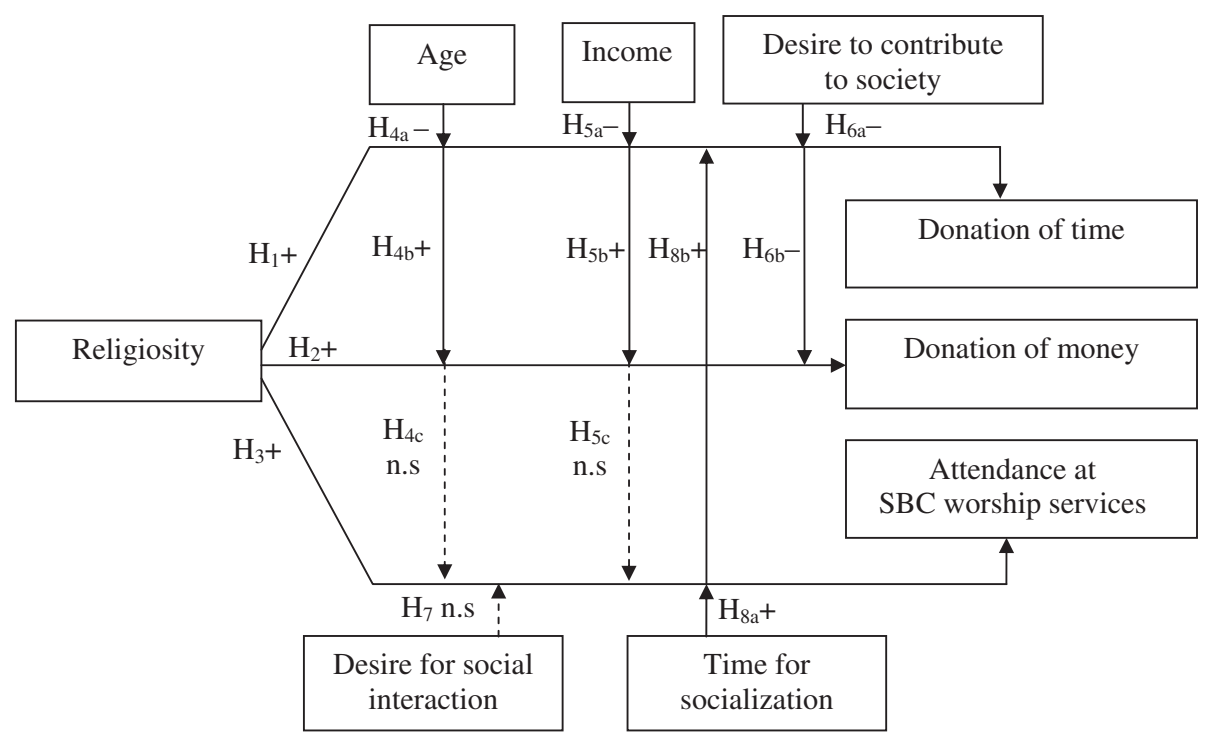

-: negative moderation; +: positive moderation; n.s.: non-significant

Fig. 1. Conceptual framework. 
In recent times well-established traditional SBCs in numerous locations around the world have shocked and disengaged segments of their membership and the community as a whole by their 'wrongdoings' (Chopko, 2003). Research needs to be conducted investigating the residual effects of these events on all forms of participation and donation across various types of SBCs. Quantifying the importance to contributors of exactly how SBCs will use donations is also imperative. A clear distinction is seen between the SBC using the funds externally (assisting the disadvantaged in the community) and internally (support of SBC staff and infrastructure). Allocating donations in accordance with the preferences of the SBC will ensure they believe their donations are generating greater value.

Another avenue of research is focused on the segment of society that provides to secular not-for-profit and charitable associations, but does not participate in an SBC, as these people are a means to grow the membership base of an SBC. An understanding of where these people prefer to spend their time and money will potentially identify opportunities for SBCs to focus their civil activities. In line with this argument, SBCs need to evaluate alternative organizational forms that distinguish their avenues for 'good works' and managing these as separate entities to their places of formalized worship. This rationalization of activities will enable the SBC to specialize their provision of services and achieve efficiency, economies of scale and more perceived value to society.

\section{Conclusions}

With the decline in participation in traditional church attendance and the proliferation of different forms of SBCs, scholars and the wider community need to understand the influences on people's behaviors of attending formalized worship and donating time and money to SBCs. This paper proposes a conceptual framework that brings new insights for consumer behavior in the field of spiritually based communities. Further, an exploratory study was conducted that corroborates the influence of religiosity on SBC participation and the moderating influences of individual characteristics such as age, income, desire to contribute to society, time for socialization, and a desire for social interaction.

This under-addressed research area deserves further investigation and a cross-cultural and cross-denominational study is proposed to extend this preliminary view and investigate further the drivers (and moderators) of participation in alternative denominations of SBCs. This paper provides preliminary insight for the structure of the charity sector, illustrating delineation between an individual's propensity to attend formalized worship and their inclination to donate time and money. Future research is encouraged seeking to understand the competing avenues for these activities and the various responses available to traditional SBCs. Suggestions for future research provide further valuable insight for the managers and leaders of spiritually based communities, given the importance of the future existence of their communities and the good works they provide.

\section{Appendix 1. Scales}

\section{Religiosity}

Adapted from Ferguson (1944), and Sawkins et al. (1997)

$1=$ Strongly disagree, $9=$ Strongly agree; $\alpha=0.94$

Religious beliefs made a positive difference in my life

The idea of a spiritual higher being or God is a mere superstition

A belief in a spiritual higher being or God is the beginning of wisdom

I am thrilled at the contemplation of a spiritual higher being or God

God is the underlying reality of my life

I have a strong degree of commitment towards my God
Desire to contribute to society

Adapted from Wilson and Musick (1997a) and Fisher and Ackerman (1998)

$1=$ Not like me at all, $9=$ Very like me; $\alpha=0.86$

I feel I would make a difference by volunteering my time

I feel it is important to help others

I can do something for a cause that is important to me

I often have tender, concerning feelings for people less fortunate than me

I feel every person who becomes involved with these organizations will make a difference

\section{Desire for social interaction}

Adapted from Greenwood and Long (2009)

$1=$ Not descriptive of me, $9=$ Very descriptive of me; $\alpha=0.86$

I try hard not to do things that will make other people avoid or reject me

I want other people to accept me

I have a strong need to belong

It bothers me a great deal when I am not included in other people's plans

My feelings are easily hurt when I feel that others do not accept me

\section{Time for socialization}

How often during a typical week do you get together with friends, neighbors or relatives?

\begin{tabular}{lll}
\hline Never & Less than once a month & Once a month \\
2-3 times a month & Once a week & $2-3$ times a week \\
Daily & & \\
\hline
\end{tabular}

Donation of time

In a typical week, about how many hours would you spend participating and being involved?

\section{Donation of money}

In a typical month, about how much money would you donate towards the work of the SBC?

\section{Attendance at SBC worship services}

In a typical week, how often do you attend religious services or places of worship?

\section{References}

Aiken, L. S., \& West, S. G. (1991). Multiple regression: Testing and interpreting interactions. Newbury Park, California: Sage Publications.

Alam, S. S., Mohd, R., \& Hisham, B. (2011). Is religiosity an important determinant on Muslim consumer behaviour in Malaysia? Journal of Islamic Marketing, 2(1), 83-96.

Albrecht, S. L., \& Heaton, T. B. (1984). Secularization, higher education, and religiosity. Review of Religious Research, 26(1), 43-58.

Andorka, R. (1987). Time budgets and their uses. Annual Review of Sociology, 13(1), 149-164.

Arham, M. (2010). Islamic perspectives on marketing. Journal of Islamic Marketing, $1(2), 149-164$.

Armstrong, J. S., \& Overton, T. S. (1977). Estimating non-response bias in mail surveys. Journal of Marketing Research, 14(3), 396-402.

Australian Bureau of Statistics (2006). Population by age and sex. Catalogue No. 3201.0

Baumeister, R. F., \& Leary, M. R. (1995). The need to belong: Desire for interpersonal attachments as a fundamental human motivation. Psychological Bulletin, 117(3), 497-529.

Benjamin, D. J., Choi, J. J., \& Fisher, G. W. (2010). Religious identity and economic behavior. National Bureau of Economic Research, Working paper 15925 (Accessed at, http://m.blog.hu/el/eltecon/file/w15925.pdf) 
Berger, P. L. (1967). The sacred canopy: Elements of a sociological theory of religion. Garden City, NJ: Doubleday.

Bonyhady, B. (2008). The future of Australian philanthropy: New uncertainties and opportunities. Accessed at, http://www.philanthropy.org.au/pdfs/philaus/Bruce_Bonyhady Opening Plenary.pdf

Bulik, B. S. (2009). Churches get religion on marketing. Advertising Age, 80(7), 4.

Burns, D. J., Reid, J., Toncar, M., Anderson, C., \& Wells, C. (2008). The effect of gender on the motivation of members of generation $Y$ college students to volunteer. Journal of Nonprofit and Public Sector Marketing, 19(1), 99-118.

Callow, M. (2004). Identifying promotional appeals for targeting potential volunteers: An exploratory study on volunteering motives among retirees. International Journa of Nonprofit and Voluntary Sector Marketing, 9(3), 261-274.

Chen, C. H. (2011). Marketing religion online: The LDS Church's SEO efforts. Journal of Media and Religion, 10(4), 185-205.

Chopko, M. E. (2003). Shaping the Church: Overcoming the twin challenges of secularization and scandal. Catholic University Law Review, 53(1), 125-160.

Cleveland, M., \& Chang, W. (2009). Migration and materialism: The roles of ethnic identity, religiosity, and generation. Journal of Business Research, 62(10), 963-971.

Cornwall, M. (1989). The determinants of religious behavior: A theoretical model and empirical test. Social Forces, 68(2), 572-592.

Craig, L., \& Bittman, M. (2008). The incremental time costs of children: An analysis of children's impact on adult time use in Australia. Feminist Economics, 14(2), 59-88.

Craig-Lees, M., Harris, J., \& Lau, W. (2008). The role of dispositional, organizational and situational variables in volunteering. Journal of Nonprofit and Voluntary Sector Marketing, 19(2), 1-24

Ferguson, L. (1944). A revision of primary social attitude scales. Journal of Psychology, $17,229-241$

Firebaugh, G., \& Harley, B. (1991). Trends in US church attendance: Secularization and revival, or merely lifecycle effects? Journal for the Scientific Study of Religion, 487-500.

Fisher, R. J., \& Ackerman, D. (1998). The effects of recognition and group need in volunteerism: A social norm perspective. Journal of Consumer Research, 25, 262-275.

Goodin, R., Rice, J. M., Bittman, M., \& Saunders, P. (2005). The time-pressure illusion: Discretionary time vs. free time. Social Indicators Research, 73(1), 43-70.

Greenwood, D. N., \& Long, C. R. (2009). Psychological predictors of media involvement: Solitude experiences and the need to belong. Communication Research, 36(5), 637-654

Gruber, J., \& Hungerman, D. M. (2008). The church versus the mall: What happens when religion faces increased competition? Quarterly Journal of Economics, 123(2), 831-862.

Hankinson, P., \& Rochester, C. (2005). The face and voice of volunteering: A suitable case for branding? International Journal of Nonprofit and Voluntary Sector Marketing, 10(2), 93-105.

Haq, F. \& Wong, H. Y. (2010). Is spiritual tourism a new strategy for marketing Islam? Journal of Islamic Marketing, 1(2), 136-148.

Hassay, D. N., \& Peloza, J. (2009). Building the charity brand community. Journal of Nonprofit and Public Sector Marketing, 21(1), 24-55.

Hillery, G. A., Jr. (1971). Freedom and social organization: A comparative analysis. American Sociological Review, 36(1), 51-65.

Hirschle, J. (2010). From religious to consumption-related routine activities? Analyzing Ireland's economic boom and the decline in church attendance. Journal for the Scientific Study of Religion, 49(4), 673-687.

Hollinger, F., Haller, M., \& Valle-Hollinger, A. (2007). Christian religion, society and the state in the modern world. Innovation: The European Journal of Social Sciences, 20(2), 133-157.

Howe, N., \& Strauss, W. (2004). Millennials rising: The next great generation. New York: Vintage.

Khraim, H. (2010). Measuring religiosity in consumer research from Islamic perspective. International Journal of Marketing Studies, 2(2), 166-179.

King, P. E., \& Boyatzis, C. J. (2004). Exploring adolescent spiritual and religious development: Current and future theoretical and empirical perspectives. Applied Developmental Science, 8(1), 2-6.

Koh, J., \& Kim, Y. G. (2003). Sense of virtual community: A conceptual framework and empirical validation. International Journal of Electronic Commerce, 8(2), 77-93.

Kossinets, G. D., \& Watts, J. (2006). Empirical analysis of an evolving social network. Science, 311, 88-90.
Kuzma, A., Kuzma, A., \& Kuzma, J. (2009). How religion has embraced marketing and the implications for business. Journal of Management and Marketing Research, 2, 1-10.

Lancaster, L. A., Dodd, S., \& Williamson, P. R. (2004). Design and analysis of pilot studies: Recommendations for good practice. Journal of Evaluation in Clinical Practice, 10(2), 307-312.

Lee, S. (2010). Marketing through sport: A case of a religious organization. International Review on Public and Nonprofit Marketing, 7(1), 87-96.

Mankowski, E. S., \& Rappaport, J. (2000). Narrative concepts and analysis in spiritually based communities. Journal of Community Psychology, 28(5), 479-493.

Mellor, D., Stokes, M., Firth, L., Hayashi, Y., \& Cummins, R. (2008). Need for belonging, relationship satisfaction, loneliness and life satisfaction. Personality and Individual Differences, 45(3), 213-218.

Miller, A. S., \& Nakamura, T. (1996). On the stability of church attendance patterns during a time of demographic change: 1965-1988. Journal for the Scientific Study of Religion, 35(3), 275-284.

Miller, A., \& Stark, R. (2002). Gender and religiousness: Can socialization explanations be saved? The American Journal of Sociology, 107(6), 1399-1423.

Mokhlis, S. (2008). Consumer religiosity and the importance of store attributes. The Journal of Human Resource and Adult Learning, 4(2), 122-133.

Mokhlis, S. (2009). Relevancy and measurement of religiosity in consumer behavior research. International Business Research, 2(3), 75-84.

Montgomery, R. D. Mitchell, M. A., Bauer, D. L. \& Turner, G. B. (2000). A changing marketplace: Marketing religion and spirituality to generation X. Journal of Ministry, Marketing and Management, 6, 35.

Mulyanegara, R. C. (2011). The role of brand orientation in church participation: An empirical examination. Journal of Nonprofit and Public Sector Marketing, 23(3), 226-247.

National Park Service (2011). Giving statistics. Accessed at, http://www.nps.gov/ partnerships/fundraising_individuals_statistics.htm

Olson, P. J., \& Beckworth, D. (2011). Religious change and stability: Seasonality in church attendance from the 1940s to the 2000s. Journal for the Scientific Study of Religion, 50(2), 388-396.

Parboteeah, K. P., Cullen, J. B., \& Lim, L. (2004). Formal volunteering: A cross-national test. Journal of World Business, 39(4), 431-441.

Park, J. Z., \& Smith, C. (2000). To whom much has been given...: Religious capital and community voluntarism among churchgoing Protestants. Journal for the Scientific Study of Religion, 39(3), 272-286.

Reich, H., Oser, F., \& Scarlett, W. (1999). Spiritual and religious development: Transcendence and transformations of the self. In K. H. Reich, F. K. Oser, \& W. G. Scarlett (Eds.), Psychological studies on spiritual and religious development: Being human: The case of religion, 2. (pp. 57-82)Scottsdale, AZ: PabstScience.

Ruiter, S., \& de Graaf, N. D. (2006). National context, religiosity, and volunteering: Results from 53 countries. American Sociological Review, 71(2), 191-210.

Sawkins, J. W., Seaman, P. T., \& Williams, H. C. S. (1997). Church attendance in Great Britain: An ordered logit approach. Applied Economics, 29(2), 125-134.

Schwadel, P. (2005). Individual, congregational, and denominational effects on church members' civic participation. Journal for the Scientific Study of Religion, 44(2), 159-171.

Schwadel, P. (2011). Age, period, and cohort effects on religious activities and beliefs. Social Science Research, 40(1), 181-192.

Schwadel, P., McCarthy, J. D., \& Nelsen, H. M. (2009). The continuing relevance of family income for religious participation: U.S. White Catholic Church attendance in the late 20th century. Social Forces, 87(4), 1997-2030.

Sundeen, R. A., Raskoff, S. A., \& Garcia, M. C. (2007). Differences in perceived barriers to volunteering to formal organizations: Lack of time versus lack of interest. Nonprofit Management \& Leadership, 17(3), 279-300.

van Teijlingen, E. R., \& Hundley, V. (2001). The importance of pilot studies. Social Research Update, 35, 1-4.

Von Sinner, R. (2007). The churches contribution to citizenship in Brazil. Journal of International Affairs, 61(1), 171-184.

Wilson, J. (2000). Volunteering. Annual Review of Sociology, 26, 215.

Wilson, J., \& Musick, M. (1997a). Who cares? Toward an integrated theory of volunteer work. American Sociological Review, 62(5), 694-713.

Wilson, J., \& Musick, M. (1997b). Work and volunteering: The long arm of the job. Social Forces, 76, 251-272.

Yip, J. (2011). Brands of faith: Marketing religion in a commercial age. Journal of Management, Spirituality E Religion, 8(1), 93-97. 